\title{
PATRIMONIO INDUSTRIAL, REVITALIZACIÓN ECONÓMICA Y COMPACIDAD URBANA EN EL POBLENOU-22@BARCELONA ¿UN NUEVO MODELO BARCELONA? ${ }^{1}$
}

\author{
Esteve Dot Jutgla \\ Montserrat Pallares-Barbera \\ Departamento de Geografía. Universitat Autònoma de Barcelona \\ Esteve.dot@uab.cat ; Montserrat.pallares@uab.cat
}

\section{RESUMEN}

La evolución de la ciudad postindustrial se reestructuró a partir de nuevas actividades, generalmente de servicios, en espacios donde previamente se habían desarrollado procesos de desindustrialización. El objetivo de este artículo es analizar como el patrimonio industrial se convierte en un elemento competitivo de la ciudad del conocimiento, dónde el sector público presionado por los movimientos ciudadanos, introduce políticas de protección de este patrimonio en favor de la construcción de la ciudad cultural. La pregunta estructural es analizar cómo se produce el patrimonio industrial, cómo se consume, y cuáles son los agentes que participan en ambos procesos; y cómo el patrimonio deviene un elemento básico del proceso de revitalización económica y de compacidad urbana en el Poblenou-22@Barcelona; finalmente se postula como esta estrategia representa un Nuevo Modelo Barcelona. La política de clústeres en el área del Poblenou, donde se localiza el plan 22@Barcelona, representó una propuesta innovadora para la transformación urbanística, económica y social de la ciudad de Barcelona.

Palabras clave: Patrimonio industrial, 22@Barcelona, desarrollo económico, ciudad simbólica, compacidad urbana, Nuevo Modelo Barcelona.

Fecha de recepción: julio 2012.

Fecha de aceptación: marzo 2015.

1 Esta investigación se ha realizado con el apoyo de los proyectos CSO 2013-46863-C3-2-R y 2014 SGR 1090. Los autores desean agradecer los comentarios de los revisores los cuales han contribuido significativamente a la mejora del artículo. 


\section{ABSTRACT}

Poblenou's intense development has been a result of the urban project 22@Barcelona (2000); which revitalized urban morphology and the area's previous economic downturn, during period 2000-2013. This article analyzes how the industrial heritage remaining in Poblenou becomes a competitive element of the project Barcelona city of knowledge, where civil society forced the public sector to introduce policies to protect this heritage for the cultural construction of the city. The structural question is to analyze how the industrial heritage was produced, how it was consumed, and which agents were involved in both processes. In addition, the focus of this paper would be to study how heritage becomes a basic element of the process of economic revitalization, of symbolic projection and of urban compactness in the Poblenou-22@Barcelona. In that, there remains an unanswered question which is the focus of this paper of whether this process represents a New Barcelona Model. The economic cluster's political approach in this area represents an innovative strategy for the urban, economic and social transformation of the whole City of Barcelona.

Keywords: Industrial heritage, urban project 22@Barcelona, economic competitiveness, symbolic city, urban compactness, New Barcelona Model.

\section{INTRODUCCIÓN}

Desde la década de los años 1980 se produce en el continente europeo el ocaso de numerosos espacios industriales urbanos como consecuencia de la crisis de la industria tradicional. Este hecho ha generado efectos cambiantes entre el espacio físico y las actividades económicas urbanas. La evolución de la ciudad postindustrial se restructuró a partir de nuevas actividades, generalmente de servicios, en espacios donde previamente se habían desarrollado procesos de desindustrialización. El objetivo de este artículo es analizar como el patrimonio industrial se convierte en un elemento competitivo de la ciudad del conocimiento, dónde el sector público introduce políticas de protección de este patrimonio en favor de la construcción de la ciudad cultural. La pregunta estructural es analizar cómo se produce el patrimonio industrial, cómo se consume, y cuáles son los agentes que participan en ambos procesos; y cómo el patrimonio deviene un elemento básico del proceso de revitalización económica y de compacidad urbana en el Poblenou-22@Barcelona; finalmente se postula como esta estrategia representa un Nuevo Modelo Barcelona. La política de clústeres en el área del Poblenou $^{2}$, donde se localiza el plan22@Barcelona, representó una propuesta innovadora para la transformación urbanística, económica y social de la ciudad de Barcelona.

2 Administrativamente, el barrio del Poblenou es uno de los diez barrios del distrito de Sant Martí (1.052,40 hectáreas). Pero en este artículo, se adopta la denominación Poblenou como el espacio delimitado por la línea del litoral, la calle de Wellington, la Avinguda Meridiana, la Avinguda Gran Vía de les Corts Catalanes, y la Rambla de Prim (Figura 3). Denominación que es también la usada popularmente y adoptada por el Ayuntamiento de Barcelona. En el año 2000 se aprueba la Modificació del Pla General Metropolità per a la renovació de les zones industrials del Poblenou -Districte d'Activitats 22@Bcn-, que es la normativa urbanística que regula la transformación urbana de parte del Poblenou, de una superficie de 198,26 hectáreas. 
Algunos espacios industriales tradicionales se transformaron recuperando viejos edificios industriales convirtiéndolos en nuevas sedes para empresas, viviendas, equipamientos y centros culturales. Esta transformación produjo un efecto acumulativo sobre el paisaje urbano que actuó como atractivo de nuevas empresas, vivienda y actividades turísticas (Pareja et al., 2007; Musterd y Murie, 2010; Pallares-Barbera, 2010). Los elementos patrimoniales de la industria tradicional formaban parte de una nueva ciudad, pero con unas funcionalidades absolutamente diferentes de antaño. La protección del patrimonio histórico industrial que se incorporó en el entorno urbano mejoró la posición competitiva de la ciudad a través de la estética y de la historia reflejada en este patrimonio; estos elementos incrementaron la calidad de vida y formaban parte de la cultura del tejido urbano. La ciudad de la segunda década del siglo veintiuno ya no es un nodo estático en el espacio, sino un confluyente de flujos de diversidad. La actividad económica monofuncional se diversificó incluyendo la comercial, la turística, el alojamiento en hoteles y residencias, los espacios de creación, las oficinas, las instalaciones culturales y los espacios verdes. Si la atracción de talento (Florida, 2005) pudo ser el determinante del crecimiento de la actividad económica de una ciudad, un espacio atractivo para el talento es el que tiene diversidades de flujos que permiten trabajar y vivir con una alta calidad de vida.

En la segunda sección de este artículo se presenta una revisión de la literatura entorno al patrimonio industrial en el proceso de revitalización urbana de la ciudad postindustrial. En primer lugar, se analiza el concepto de patrimonio industrial; en segundo lugar, se estudia su transformación en nuevas funciones del territorio, como recursos cultural, turístico, residencial, empresarial y equipamientos. En tercer lugar, se discute el proceso de creación de imagen y de simbolismo de la ciudad, como una estrategia de política de desarrollo y atracción económica a partir de la incorporación de recursos patrimoniales.

La tercera sección del artículo se centra en el estudio del conjunto histórico patrimonial en el área del Poblenou; y en cómo éste se ha ido formando, analizando primero una ordenanza del año 1979 (Ajuntament de Barcelona, 1979) y a continuación, tres figuras de planeamiento urbanístico (dos en el año 2000 y una en el 2006) (Ajuntament de Barcelona, 2000a, 2000b y 2006). La Guía para Visitar y Descubrir el Distrito 22@Barcelona (2010), publicada coincidiendo con el décimo aniversario del proyecto 22@Barcelona, es una herramienta de difusión de esta área de Barcelona (Ajuntament de Barcelona, 2010). La sociedad municipal 22 ARROBA BCN, S.A.U. fue el principal agente institucional implicado en la formación y desarrollo del patrimonio. Fue creada en el año 2000 por el Ayuntamiento de Barcelona con la finalidad de impulsar y gestionar, mediante el planeamiento, la transformación del 22@Barcelona; y para la promoción de las áreas industriales y productivas de la ciudad con calificación urbanística 22@ (Casellas y Pallares-Barbera, 2009). En la reutilización del patrimonio industrial se han incorporado diversas funciones, tanto públicas como privadas. Por un lado, se han dedicado espacios rehabilitados a equipamientos de uso social, como bibliotecas, centros cívicos, y universidades; por otro lado, se han construido viviendas, empresas, equipamientos de apoyo a la actividad económica, y centros de formación.

En la cuarta sección se analizan como caso de estudio 3 antiguos edificios fabriles ubicados en el 22@Barcelona (Figura 3): Passatge del Sucre, Can Gili Vell, y Can Gili Nou, donde su uso ha cambiado de industrial a residencial tipo loft. Particularmente, se examina como 
la protección patrimonial constituye una ventaja comparativa en la promoción de la venta de las viviendas. A continuación, en la quinta sección se contestan 2 preguntas a partir de dos metodologías. Primero, ¿Cómo el patrimonio industrial ha llegado a formar parte de la oferta cultural para visitantes? Por lo que se exploran guías turísticas. Segundo, ¿Quiénes son los visitantes, qué visitan y qué opinión tienen de lo que visitan? Por lo que se hacen encuestas a directores de hoteles (2012). Finalmente, las conclusiones y referencias bibliográficas cierran este artículo.

\section{EL PATRIMONIO INDUSTRIAL EN EL PROCESO DE REVITALIZACIÓN URBANA Y LA CIUDAD SIMBÓLICA}

En general, el interés por la conservación y reutilización del patrimonio por su legado cultural ha llevado a instituciones y organismos nacionales e internacionales a la patrimonialización de los paisajes (Hudson, 1963; Gómez, 2013). En este proceso algunas veces se pierden las características impresas en su uso secular y la intervención pública amenaza con la banalización del espacio, anteriormente vernacular y vivido. A nivel conceptual se pueden encontrar diferencias entre la denominación patrimoine (de origen francés y latino) y de heritage (de origen anglosajón), dónde el primero se refiere a una dimensión económica dominante del bien de herencia transmitido por parte de los ascendientes; y el segundo representa el valor arqueológico, histórico e identitario.

En particular, el patrimonio industrial urbano empieza a considerarse como un bien a proteger en Gran Bretaña en los años 1950; y como bien cultural aparece como eje estructurante en las políticas de desarrollo urbano y económico de la ciudad a partir de los años 1990 en Europa; donde los elementos patrimoniales forman parte de las estrategias de la nueva ciudad, a partir de la refuncionalidad del espacio. El patrimonio industrial ha devenido un elemento a considerar en la ordenación, la planificación y las estrategias de desarrollo territorial en su triple condición de recurso, memoria del lugar y rasgo de identidad colectiva. Una buena gestión del patrimonio industrial y su reutilización con fines culturales se convierte en un factor de desarrollo local (Capel, 1996; Benito, 2002, 2010; Álvarez, 2010). Ante los nuevos retos del espacio global del siglo veintiuno, las acciones estratégicas de las instituciones locales se estructuran a partir de la creación de imagen y de la proyección simbólica de la ciudad, y permiten aprovechar los recursos locales específicos de tipo cultural para el posicionamiento e internacionalización de las ciudades.

\section{II.1. Aproximación conceptual a patrimonio industrial}

Dentro del concepto de patrimonio, el patrimonio industrial se presenta como un elemento patrimonial cultural:

«al que se le reconoce un interés histórico-artístico y un valor material y social cuyo inventario, protección y conservación se hacen imprescindibles para comprender la sociedad contemporánea y valorar la herencia recibida de la era industrial» (Benito, 2010: 354). 
La discusión sobre el concepto de patrimonio industrial adquirió a finales del siglo veinte una gran notoriedad a escala internacional. La existencia de organismos dedicados a su estudio y protección, y la toma de conciencia de la sociedad civil del valor de dicho patrimonio es una muestra de ello (Tatjer, 2008; Pardo, 2010).

El concepto de patrimonio industrial tiene su origen en el movimiento proteccionista de los años 1950 en Gran Bretaña; donde aparece la necesidad de conservarlo y protegerlo ante los embates de una nueva concepción de las actividades económicas en las ciudades que habían surgido de la revolución industrial. Para tal fin nacieron asociaciones dedicadas a inventariar y conservar el patrimonio industrial (Casanelles, 1988). En general, en el resto de Europa, la transición de una economía productiva hacia una economía de los servicios entre los años 1970 y 1980 fue la chispa que comenzó el proceso; donde las fábricas se trasladaron a los suburbios y el parque industrial remanente en las zonas urbanas fue quedando obsoleto en pocos años.

Por su parte, el estudio de la arqueología industrial y la conservación, protección, difusión e interpretación del patrimonio industrial a nivel internacional se basa en la labor del Comité Internacional para la Conservación del Patrimonio Industrial (TICCIH ${ }^{3}$ en inglés), fundado en 1978. La importancia de esta organización es que reúne a instituciones museísticas, asociaciones y universidades que trabajan en el campo de la arqueología y el patrimonio industrial de cuarenta países. El TICCIH es desde finales de la década de 1980, el organismo asesor en cuestiones de patrimonio industrial del Consejo Internacional para la Conservación y la Restauración de Monumentos y Sitios (ICOMOS ${ }^{4}$ en inglés) de la UNESCO, para la selección de los monumentos, sitios y paisajes de la industria.

Uno de los principales documentos elaborados por el TICCIH es la Carta de Nizhny Tagil sobre el Patrimonio Industrial (2003), que es un documento de referencia para los países, y establece una definición de patrimonio industrial:

«El patrimonio industrial se compone de los restos de la cultura industrial que poseen un valor histórico, tecnológico, social, arquitectónico o científico. Estos restos consisten en edificios y maquinaria, talleres, molinos y fábricas, minas y sitios para procesar y refinar, almacenes y depósitos, lugares donde se genera, se transmite y se usa energía, medios de transporte y toda su infraestructura, así como los sitios donde se desarrollan las actividades sociales relacionadas con la industria, tales como la vivienda, el culto religioso o la educación [...] El período histórico de principal interés se extiende desde el principio de la Revolución Industrial, la segunda mitad del siglo XVIII, hasta la actualidad, incluida». (TIC$\mathrm{CIH}, 2003: 1)$

Esta definición incluye en el concepto de patrimonio industrial el valor de la historia, la técnica, la historia social, la arquitectónica, y la ciencia. A pesar que las definiciones de esta organización no son vinculantes para los Estados, sí que representa un referente importante

3 The International Committee for the Conservation of the Industrial Heritage. [En línea]. <http://www.ticcih.org/> [Consulta: 31 de octubre de 2014].

4 The International Council for Monuments and Sites. [En línea]. <http://www.icomos.org/> [Consulta: 31 de octubre de 2014]. 
para abordar el tratamiento del patrimonio industrial. Su trabajo en cuanto a la conceptualización permite un estudio del bien patrimonial para la concienciación de la sociedad, para estimar su pérdida y, en consecuencia, defender su protección (Ortúñez, 2009).

\section{II.2. La transformación del patrimonio industrial arquitectónico: producto turístico, residencial tipo loft, y actividad intensiva en conocimiento y equipamiento}

En el proceso de reorganización del tejido físico y urbano de una ciudad con tradición industrial aparece el patrimonio industrial como producto de consumo turístico. La promoción del patrimonio como turismo cultural (heritage tourism, Richards, 2001a) reactiva la conservación de los bienes patrimoniales, parando en general su proceso de decadencia (Marchena, 1998). Las bases para atraer turismo cultural se fundamentan en estrategias que convierten los bienes patrimoniales en símbolos de atracción turística (Richards, 2001b). Estos símbolos deben proporcionar experiencias y emociones, y deben tener rasgos únicos o singulares para diferenciarse del resto y atraer y retener visitantes. Por tanto, estos símbolos son una de las piezas centrales del sistema turístico, ya que actúan como catalizadores para la provisión del resto de servicios y productos turísticos puestos a disposición de los visitantes.

El patrimonio industrial se convierte en producto turístico a partir de incorporar valor añadido al producto inicial (proceso de «comodificación», commodification en inglés (Marx, 1986; Polanyi, 2001)) que se revaloriza para un uso determinado, resaltando aquellos factores que serán importantes para la demanda final. Las estrategias para la comodificación de un recurso patrimonial arquitectónico son variadas, presentando todas ellas costes de inversión y planes de comercialización con diferentes resultados. Por ejemplo, en el desarrollo de rutas de descubrimiento de patrimonio, la comercialización es directa cuando se produce en unos puntos determinados, como pueden ser los museos, monumentos o parques naturales; o la comercialización es complementaria cuando la oferta se produce a través del sector de la hostelería. La comercialización puede ser indirecta cuando quien la realiza son intermediarios o detallistas, como agencias de viajes. Las vías de promoción turística del patrimonio más frecuentes son a partir de material impreso (folletos, guías, o carteles); y de utilización de la Web, que multiplica el número de receptores potenciales y constituye, por tanto, el mayor y más rentable escaparate para dar a conocer un producto turístico (Ramos, 2007).

Desde los años 1950 se ha producido la adaptación y cambio de uso de antiguas fábricas convirtiendo el espacio diáfano en viviendas tipo loft. El origen se encuentra en la ciudad de Nueva York, concretamente en los barrios del Soho, Tribeca y Nolita, como consecuencia de la búsqueda por parte de profesionales liberales, estudiantes y artistas de espacios de bajo coste en los que vivir y trabajar al mismo tiempo. Los precios elevados del parque inmobiliario residencial hicieron que las fábricas y almacenes en desuso cobraran importancia como vivienda (Zukin, 1989; Lloyd, 2006). Esta tendencia se extendió en los años 1970 a Europa, introduciéndose en barrios como el Soho en Londres o Pigalle en París; y posteriormente, en los años 1990 en otras ciudades europeas como el barrio de Gràcia en Barcelona (Cano, 2012). 
El loft es un espacio amplio y diáfano que se compone de estancias flexibles facilitando tanto el uso doméstico como profesional. Los diferentes usos mantienen las características arquitectónicas y el espíritu industrial de los inmuebles, siendo la altura, los espacios diáfanos y las instalaciones vistas, las señas de identidad de los lofts. La imagen del loft ha ido cambiando en sus casi setenta años de historia. Estas superficies habitadas inicialmente por gente de poco poder adquisitivo, y a menudo en la ilegalidad, se han convertido en viviendas de alto poder adquisitivo. Desde finales del siglo veinte se ha impulsado su rehabilitación con fines comerciales en muchas ciudades donde aún existen edificios industriales obsoletos (Barcelona, Berlín, Chicago, Glasgow, Manchester, Nueva Orleáns y París). El éxito de los lofts ha inducido a que las constructoras de viviendas se interesen por las zonas céntricas de las ciudades, los espacios abiertos en las viviendas y la arquitectura contemporánea. Los promotores utilizan el concepto de patrimonio convertido en loft para sus estrategias publicitarias. Así pues, frases como «loft de estilo neoyorkino»o «edificios históricos o de principios de siglo veinte», juntamente con las características físicas (material, aperturas, estructura) del loft son comunes para reflejar el atractivo urbano y original de las décadas pasadas tanto en Estados Unidos como en Europa (Cano, 2012). El movimiento loft sigue en expansión aunque el estilo de vida inicial que lo caracterizaba ha perdido su significado más bohemio, y en pleno siglo veintiuno el loft es, en general, dedicado a un público de gustos sofisticados y alta capacidad adquisitiva.

Las actividades de nueva economía, englobando conocimiento y creatividad, se han concentrado en clústeres urbanos (Casellas y Pallares-Barbera, 2009), donde, muy habitualmente han aprovechado recursos patrimoniales arquitectónicos industriales para ubicar la empresa (Hayward, 2006). Este proceso ha producido una regeneración de espacios productivos históricos degradados y una renovación de usos del suelo urbano.

En Europa, ejemplos de transformación y de rehabilitación urbana han seguido procesos bottom-up centrados, primero en la ocupación de espacios industriales obsoletos por actividades artísticas; que han conllevado a la gentrificación del barrio. Iniciándose transformaciones de rehabilitación arquitectónica de vivienda y, consecuentemente, substitución social. Shoreditch en Hackney (Londres) es un buen ejemplo de este fenómeno, donde la chispa regenerativa empezó a partir de la iniciativa privada de creadores relacionados con el sector media, publicidad y audiovisuales (Pallares-Barbera y Leonard, 2007). En América, Nueva York fue paradigmático en la recuperación de espacios patrimoniales y su dedicación a otros usos, de vivienda, y terciario, entre otros. Éste es el caso de de la transformación experimentada en el barrio de Meatpacking en Manhattan dónde hacia finales de los años 1990, diseñadores de moda y diseño gráfico, arquitectos, artistas y creativos se mudaron ocupando edificios en desuso, anteriormente mataderos y plantas empacadoras de carne (Meatpacking Improvement Association, 2014).

En España, las intervenciones sobre el patrimonio industrial arquitectónico urbano son relativamente recientes, mayoritariamente a partir de los años 2000. La transformación de las viejas fábricas ha dado como resultado usos diversos como empresas, hoteles, museos, bibliotecas, archivos, espacios comerciales, parques empresariales (Calderón, 2007) o centros culturales. Por ejemplo, CaixaForum en Barcelona y en Madrid (la fábrica Casaramona y la central eléctrica del Mediodía, respectivamente), o la sala de exposiciones Canal de Isabel II en Madrid (antiguamente depósito de aguas) (Pardo, 2010). 


\section{II.3. La creación de imagen y la proyección simbólica en la estrategia de ciudad cultural}

Las ciudades globales integran la actividad económica y cultural como una estrategia de regeneración urbana dando como resultado la ciudad cultural. El diseño de políticas urbanas de tipo cultural desde las instituciones públicas, y especialmente desde la administración local, contempla los mega-proyectos pero tambien los eventos temporales con el propósito de atraer a inversores en torno a la producción y consumo de la cultura y las artes. El proceso de creación de una marca y el simbolismo cultural acompañan a la regeneración de la ciudad cultural (Yeoh, 2005).

Los factores de atracción de la ciudad vienen dados por el grado de especificidad y de singularidad que le son propios (Balibrea, 2004). Por tanto, la promoción de una ciudad es la consolidación de una imagen atractiva y la proyección de unos símbolos locales hacia un ámbito global muy competitivo. A finales del siglo veinte las políticas urbanas se diseñaron para incluir la ciudad cultural en unos mercados de producción y de consumo global. Esto hizo que se produjera una creciente competencia entre ciudades de todo el mundo para atraer inversores y actividad económica. En este contexto, la percepción y la imagen mental que se genera sobre las ciudades se convirtió en un componente importante del futuro éxito o fracaso económico de una urbe (Ashworth y Voogd, 1990). Esto convirtió a las políticas de desarrollo de las ciudades en programas de marketing, para promocionar una imagen urbana que atrajese el capital global.

A partir de los años 1980, el patrimonio industrial arquitectónico empezó a considerarse relevante como elemento cultural y específico de las ciudades europeas, en el momento que el sector público lo incluyó en el fomento y la promoción de políticas culturales. El objetivo de los agentes públicos fue la utilización de la cultura, en un sentido amplio, como estrategia de desarrollo económico local. El cambio de imagen hacia una ciudad cultural produjo un impacto incrementando la atracción de nuevos residentes, empresas y turistas en algunas ciudades. Así, desde comienzos de los años 1980, algunas ciudades europeas apostaron por políticas culturales incluyendo la renovación urbana.

En antiguas ciudades industriales, la construcción de centros culturales, como el museo Guggenheim en Bilbao, se constituyeron como motores de la regeneración urbana (Bianchini y Parkinson, 1993). La ciudad cultural, desde los años 1990, intentó captar actividades de nueva economía:

«los espacios de nueva economía marcan un nuevo ámbito de convergencia entre la actividad económica y la cultura» (Krueger y Gibbs, 2007: 100).

Donde los trabajadores cualificados en esta nueva economía estaban especialmente atraídos por la calidad de vida y los atractivos del espacio urbano. Para esta clase creativa (Florida 2002; 2005) la cultura y la solera de una ciudad eran elementos clave. Por lo que las ciudades dirigieron políticas de promoción económica remarcando sus nuevos productos culturales construidos a partir de resaltar sus especificidades para atraer empresas de nueva economía y nuevos trabajadores de esta clase creativa.

El esfuerzo por crear una imagen de ciudad atractiva iba acompañado por la proyección de símbolos. La evolución de las políticas locales promocionó la ciudad simbólica, resal- 
tando aquel conjunto de símbolos que podían hacer más competitiva la ciudad en el ranking internacional. La ciudad simbólica, a diferencia de la ciudad industrial, que se caracterizaba por una economía manufacturera dónde las ventajas competitivas espaciales venían dadas por la reducción de costes de producción y el mercado, se convirtió en centro de atracción de personas que querían visitarla o establecerse, en parte por sus símbolos (Pallares-Barbera, 2010). En consecuencia, la localización de nuevas empresas venía determinada por la eficiencia simbólica creada, y no por la eficiencia del bajo coste.

En la economía simbólica, los símbolos culturales pueden ser elementos que originalmente no han sido concebidos como bienes culturales, pero que han formado y forman parte de la «construcción de la ciudad». En este sentido, el patrimonio histórico industrial es un buen ejemplo, donde en el siglo veintiuno se convierte en un símbolo, cuando fue previsto anteriormente para otro fin. Estas variables de la economía simbólica en la trama urbana son multiplicadores que favorecen el crecimiento económico y posicionan la ciudad en el estatus global. En la ciudad actual se reconocen unos valores culturales intrínsecos como símbolos propios, que son caracteres locales y forman parte de sus atractivos, de sus fortalezas y de su competitividad (Pallares-Barbera, 2010).

\section{EL ORÍGEN HISTÓRICO, LA REGULACIÓN URBANÍSTICA Y LA PROMOCIÓN DEL PATRIMO- NIO INDUSTRIAL EN EL POBLENOU-22@BARCELONA}

En los siglos diecinueve y veinte se formaron los elementos arquitectónicos representativos del pasado industrial del Poblenou. La gran concentración de edificios fabriles en el área surgió en el contexto de la revolución industrial en Barcelona. La necesidad de nuevos espacios para las fábricas mayoritariamente del sector textil, se vio satisfecha por los terrenos del Poblenou (cercanos al centro de la ciudad y con unas características orográficas favorables). A mediados del siglo veinte se dio un cambio en la evolución del espacio productivo debido al retroceso del sector textil. En consecuencia hubo el cierre de las fábricas. Parte de los inmuebles industriales vacios del Poblenou sirvió para albergar, en las décadas de 1960 y 1970, otras actividades económicas como talleres, almacenes, garajes, y empresas de transporte. Mientras que la otra parte de los edificios históricos quedó obsoleta dejando el paisaje industrial en un estado de abandono, en el periodo 1980-2000.

El proceso de creación del patrimonio industrial del Poblenou-22@Barcelona fue liderado por el Ayuntamiento de Barcelona a través de tres figuras urbanísticas que regularon los elementos patrimoniales. La Modificació del Pla General Metropolità per a la renovació de les zones industrials del Poblenou-Districte d'Activitats 22@BCN (MPGM) hecha en el año 2000, es la que determina dentro del plan 22@Barcelona, la catalogación y protección del patrimonio industrial del Poblenou (Ajuntament de Barcelona, 2000a). A partir del Pla especial del patrimoni arquitectònic històric i artístic de la ciutat de Barcelona. Districte de Sant Martí. Patrimoni industrial del Poblenou (PEPA), que se aprueba en el 2000 y se modifica en el 2006, se otorga el régimen jurídico a los edificios patrimoniales así como la regulación de la protección (Ajuntament de Barcelona, 2000b, 2006). El proceso de promoción del propio patrimonio industrial se produce a partir de la Guía para Visitar y Descubrir el Distrito 22@Barcelona (2010) (Ajuntament de Barcelona, 2010). 


\section{III.1. Historia industrial del Poblenou}

Los elementos patrimoniales del Poblenou situados en el antiguo municipio de Sant Martí de Provençals, actual distrito de Sant Martí ${ }^{5}$, que fue uno de los grandes núcleos industriales del Pla de Barcelona, junto con Gràcia, Sants, Sant Andreu o les Corts. Las actividades de blanqueo, estampado y tintorería de tejidos eran propias del Poblenou en el siglo diecinueve, lugar que era conocido como el Manchester Catalán. La gran concentración de fábricas y almacenes dedicados al sector textil fueron importando el estilo arquitectónico y la técnica de organización y producción inglesas. En el año 1888, coincidiendo con la Exposición Universal de Barcelona, se registraban en Sant Martí de Provençals 243 fábricas y almacenes, la mayoría de ellas $(152 ; 62,5 \%)$ localizadas en el Poblenou (Arxiu Històric del Poblenou, 2001).

La industrialización de Sant Martí se inició entre finales del siglo dieciocho y principios del diecinueve con las primeras fábricas de indianas, «prados de indianas». La proximidad a Barcelona, la abundancia de agua, y la disponibilidad de suelo, fueron factores de localización determinantes. Consecuentemente, a finales del siglo diecinueve el Poblenou llegó a ser el territorio con más concentración industrial de España en la fabricación de tejidos de algodón. En este siglo, el paisaje industrial lo completaba la industria harinera, metalúrgica, curtiduría, química, la alimentación y otras manufacturas (Figura 1, Figura 2). En los espacios libres entre fábricas se levantaron viviendas, generalmente pobremente construidas y con deficientes condiciones higiénicas. Las epidemias de cólera, tifus o viruela, hasta bien entrado el siglo veinte, produjeron gran mortandad entre los obreros; y donde el cooperativismo tuvo una fuerte implantación.

Figura 1

CAN VILELLA, ENTRE LAS CALLES LLULL Y BACH DE RODA (1920)

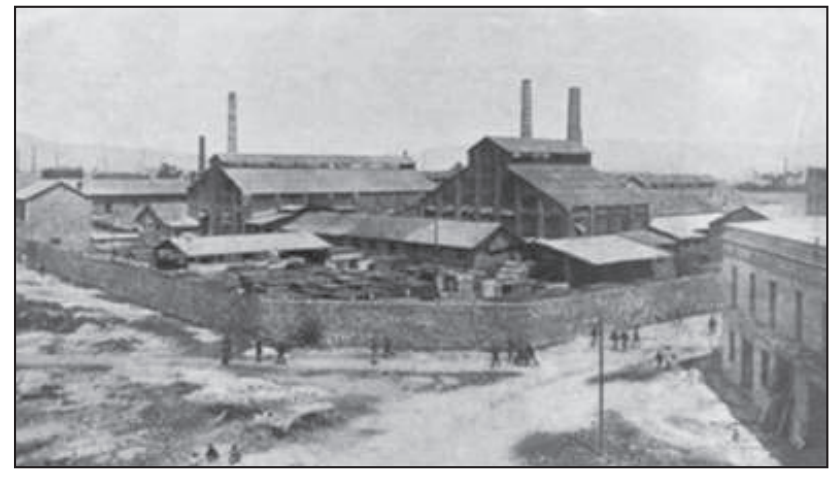

Fuente: Arxiu Històric del Poblenou (2014).
Figura 2

CAN GIRONA CON LA TORRE DE LAS AGUAS (1930)

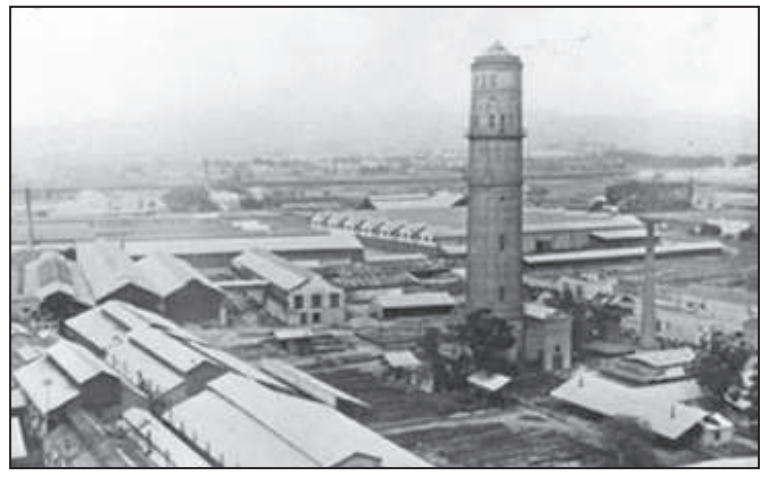

A mediados de los años 1950 la actividad fabril del Poblenou y del conjunto del distrito de Sant Martí experimentó un proceso de declive económico. El aumento del precio del combustible y la localización del sector textil en otros puntos fuera de España produjo una

5 Hasta 1897 la población de Sant Martí de Provençals, uno de los 10 distritos actuales de la ciudad de Barcelona, formó municipio propio. 
disminución de la actividad textil. El número total de establecimientos industriales se redujo progresivamente desde mediados de 1960, comenzando un proceso de desindustrialización que originó grandes solares vacíos y edificios desocupados que, en parte, volvieron a ser ocupados por empresas de metal, de transportes, talleres y almacenes procedentes del resto de Barcelona. En general la pérdida de actividad económica se consolidó, dejando el Poblenou en una situación crítica a finales de los años 1980 y convirtiéndose en un contexto urbano obsoleto. La revalorización urbanística de buena parte de este territorio vino con la celebración de los Juegos Olímpicos de Barcelona en 1992 (Arxiu Històric del Poblenou, 2001).

\section{III.2. Desde la Ordenança sobre protecció del patrimoni arquitectònic, històric $i$ artístic de la ciutat de Barcelona (1979) al 22@Barcelona (2000): Creación de patrimonio y cambios de usos}

A escala de distrito de Sant Martí, la primera iniciativa de protección del patrimonio histórico se sustentó en la Ordenança sobre protecció del patrimoni arquitectònic, històric i artístic de la ciutat de Barcelona del 1979 que definió el Catálogo de patrimonio histórico artístico de la ciudad de Barcelona (Ajuntament de Barcelona, 2014). Este catálogo constituyó un avance en la valoración del patrimonio, pero no resolvía la contradicción existente entre la afectación urbanística y la protección de un elemento concreto. Ante una afectación urbanística se establecía que era factible la descatalogación y consiguiente derribo de un edificio si existían «previsiones de planeamiento de interés público prevalente» (Ajuntament de Barcelona, 1979: 3). La catalogación y protección de los inmuebles históricos y artísticos de Barcelona recogía unos 1.200 edificios protegidos, localizados en su mayor parte en los distritos de Ciutat Vella y Eixample. En contraposición, el distrito de Sant Martí sólo tenía 5 edificios protegidos en este catálogo y ninguno de ellos era industrial (Hostench, 2010).

En el año 1986 el Comité Olímpico Internacional concedía la sede de los Juegos Olímpicos de 1992 a la ciudad de Barcelona. Con ello se creaba la necesidad de vivienda para los atletas participantes, además de los equipamientos culturales y deportivos, hoteles, oficinas y salas para la realización de congresos en la ciudad. La ubicación de este conjunto urbanístico se produjo en el barrio de Icaria ${ }^{6}$, aprovechando el momento coyuntural para renovar urbanísticamente un tejido industrial en obsolescencia y degradación. El derribo de Icaria no tuvo en cuenta ni valoró ningún elemento preexistente y supuso la pérdida de un valioso patrimonio de arquitectura industrial formado por fábricas de medianos del siglo diecinueve e inicios del siglo veinte (Capel, 1996; Caballé, 2010). A partir de iniciativas de instituciones se produjeron proyectos para estudiar y conservar documentalmente el barrio que desaparecía debido a las obras iniciadas a finales de 1980. El Arxiu Històric del Poblenou publicó Nou viatge a Icària (1990) para la documentación escrita y gráfica del origen y la evolución de las principales industrias y espacios públicos del barrio. El Servei d'Activitats Arqueològiques, dependiente en aquel momento del Museu d'Història de la Ciutat de Barcelona (MHCB), junto con el Servei de Protecció del Patrimoni Monumental, dependiente del Ayuntamiento, realizó un proyecto de documentación histórica del antiguo barrio fabril (Caballé et al., 1991).

6 Icaria es el actual barrio de la Vila Olímpica (el Poblenou) que se situaba entre la vía del antiguo ferrocarril de la línea de Mataró y las playas. El nombre de Icària viene dado en el 1855 por Ildefons Cerdà, influenciado por compañeros de una comunidad de tipo socialista utópico (Arxiu Històric del Poblenou, 2001). 
En el año 1993 la Generalitat de Catalunya aprobó la Llei del Patrimoni Cultural Català ${ }^{7}$. La ley partía de un concepto amplio del patrimonio cultural y establecía la protección, la conservación, la investigación, la difusión y el fomento del patrimonio cultural:

«El patrimonio cultural catalán está integrado por todos los bienes muebles o inmuebles relacionados con la historia y la cultura de Cataluña que por su valor histórico, artístico, arquitectónico, arqueológico, paleontológico, etnológico, documental, bibliográfico, científico o técnico merecen una protección y una defensa especiales, de manera que puedan ser disfrutados por los ciudadanos y puedan ser transmitidos en las mejores condiciones a las futuras generaciones» (Generalitat de Catalunya, 1993: 2).

La Llei establece tres categorías de protección del patrimonio cultural, con grados de mayor a menor protección tanto en bienes muebles, inmuebles como en bienes inmateriales: los bienes culturales de interés nacional, los bienes catalogados y el resto de bienes integrantes del concepto de patrimonio cultural.

Dentro de este escenario creado por la Llei de la Generalitat, en el año 1994 el Ayuntamiento de Barcelona revisó el catálogo del año 1979, incluyendo la categoría de patrimonio industrial. En el año 2000, en una zona del Poblenou, el proyecto 22@Barcelona acentuó la protección y catalogación del patrimonio industrial del Poblenou. El marco normativo urbanístico y de protección del 22@Barcelona permitió una modificación y ampliación del catálogo del 1994. El Ayuntamiento de Barcelona lideró la regulación a través de los planes especiales de protección.

Esta ampliación de catálogo fue fruto de una movilización cívico social. En este periodo, entre los años 2000 y 2006 amplios sectores sociales se movilizaron para conseguir salvar edificios emblemáticos que el Ayuntamiento no consideraba como tales. El sector cívico social, a través de la reivindicación colectiva, logró que se conservasen edificios simbólicos para el barrio y que el uso de estos edificios se dedicase en parte a equipamientos sociales de tipo cultural y recreativo para la ciudadanía (Checa, 2007; Clarós, 2007, 2010). La Associació de veïns del Poblenou y el Grup de Patrimoni del Forum de la Ribera de Besòs (GPFRB, 2005a, 2005b, 2006a, 2006b), formados por colectivos de vecinos, intelectuales y científicos, que desde el año 2002 trabajaba para conseguir la conservación del patrimonio industrial de Can Ricart, en el Poblenou, entre otros, fueron los grandes impulsores de la conservación del patrimonio en el Poblenou (Tatjer, 2005a, 2005b, 2008; Tatjer et al., 2005; Dot et al., 2012).

La MPGM hecha en el año 2000 determinó dentro del plan 22@Barcelona, la catalogación y protección del patrimonio industrial del Poblenou; a partir del PEPA, que se aprobó

7 A nivel nacional, los municipios de Barcelona y Madrid tienen un desarrollo de instrumentos de protección de patrimonio histórico parecido en su evolución temporal y jurídica. Así, la normativa de Madrid contempla en el Plan General de Ordenación Urbana de Madrid de 1997, los instrumentos de protección del patrimonio histórico: 1) La normativa de carácter general, adaptada a la particularidad de cada elemento; y 2) El catálogo General de Edificios Protegidos, donde se analiza individualmente cada elemento a proteger y se regula el tratamiento específico más idóneo para su mejor protección. Estos instrumentos operan de acuerdo con la Ley 10/1998, de 9 de julio, de Patrimonio Histórico de la Comunidad de Madrid, que tiene por objeto el enriquecimiento, salvaguarda y tutela del Patrimonio Histórico ubicado en la Comunidad de Madrid (Ayuntamiento de Madrid, 1997). 
en el 2000 y se modificó en el 2006. El PEPA catalogó edificios y elementos de la estructura urbana que venían jurídicamente protegidos a diferentes niveles. La categoría superior la forman los elementos con nivel A (Bien Cultural de Interés Nacional), decididos por la Generalitat (Llei de 1993). La siguiente categoría la forman los de nivel B (Bien Cultural de Interés Local), definidos por el Ayuntamiento y ratificados por la Generalitat. Los elementos pertenecientes al nivel C (Bien de Interés Urbanístico) y nivel D (Bien de Interés Documental) son competencia absoluta del Ayuntamiento. Para las tres primeras categorías es obligado el mantenimiento del edificio y no es posible el derribo (en el caso del nivel C sólo parcialmente), mientras que en el nivel D se permite el derribo después de presentar y ser aprobado un estudio histórico-arquitectónico.

Con la Modificación del PEPA en el 2006 se catalogaron 68 nuevos edificios industriales, consolidando un total de 114 edificios protegidos (Ajuntament de Barcelona, 2006), de los cuales solo Can Ricart pasó a ser considerado de nivel A. El PEPA reguló los usos para la reutilización del patrimonio industrial que se ha diversificado con funciones alternativas desde universidades, centros sociales, actividad económica, y edificios residenciales. El planeamiento urbanístico define los siguientes usos: uso destinado a universidades y a equipamiento de apoyo a las empresas, con la clave 7@; uso destinado a equipamientos comunitarios, con la clave 7 a y $7 \mathrm{~b}$; usos destinados a actividades económicas con la clave 22@, que incluye el suelo destinado a terciario y actividades@ (con la clave 22@t2) y el destinado a residencial de tipología loft (con la clave 22@t1).

Como clave 7@, entre los más destacables, existen los siguientes edificios: la antigua fábrica Ca l'Aranyó que se ha transformado en el Campus de la Comunicación de la Universitat Pompeu Fabra. La fábrica Can Jaumandreu es sede de la Universitat Oberta de Catalunya. En la fábrica Can Framis se ubica el Museu Can Framis de la Fundació Vila Casas. En la nave Francesc Munné en la actualidad se ubica la Escuela de diseño BAU. La colonia de Can Ricart acoge el equipamiento cultural Hangar.

Como clave 22@, se remarcan los siguientes espacios: Naus de la familia Ametller, antiguamente sitio dedicado al sector de la alimentación, ha sido ocupado por la empresa del sector media Teuve. La antigua fábrica Metales y Platería Ribera (Can Culleretes), con producción de cubiertos de mesa que ha sido adaptada a la empresa T-Systems, del sector TIC. En Josep Canela e Hijos se ubica ahora la Comisión del Mercado de Telecomunicaciones. La misma clave 22@ permite el uso residencial tipo loft, por ejemplo en el Passatge del Sucre, Can Gili Vell y Can Gili Nou (estudiados en detalle en el epígrafe IV).

\section{III.3. La promoción del patrimonio en el Poblenou: la Guía para Visitar y Descubrir el Distrito 22@Barcelona (2010)}

El proceso de revitalización urbana en el Poblenou-22@Barcelona incluyó la promoción del patrimonio industrial en la oferta cultural de la ciudad. El Ayuntamiento de Barcelona diseñó la Guía para Visitar y Descubrir el Distrito 22@Barcelona (2010) para da a conocer el entorno urbano del Poblenou que forman parte de los nuevos elementos arquitectónicos de consumo en la ciudad simbólica. Esta arquitectura sirve para favorecer el lugar como punto de atracción turística y ayudar a la construcción de la «marca Barcelona». 
La Guía destaca algunos elementos patrimoniales industriales del Poblenou que presentan un cambio de funciones en los diferentes edificios. Los puntos de interés de la Guía se organizan en tres itinerarios por el Poblenou: 1 «Patrimonio Histórico-Artístico del Poblenou», 2 «Innovación Tecnológica y Empresarial», y 3 «Espacios Públicos y Culturales» (Figura 3).

Figura 3

TRES ITINERARIOS POR EL DISTRITO DE LA INNOVACIÓN A TRAVÉS DE LA GUÍA PARA VISITAR Y DESCUBRIR EL DISTRITO 22@BARCELONA (2010)

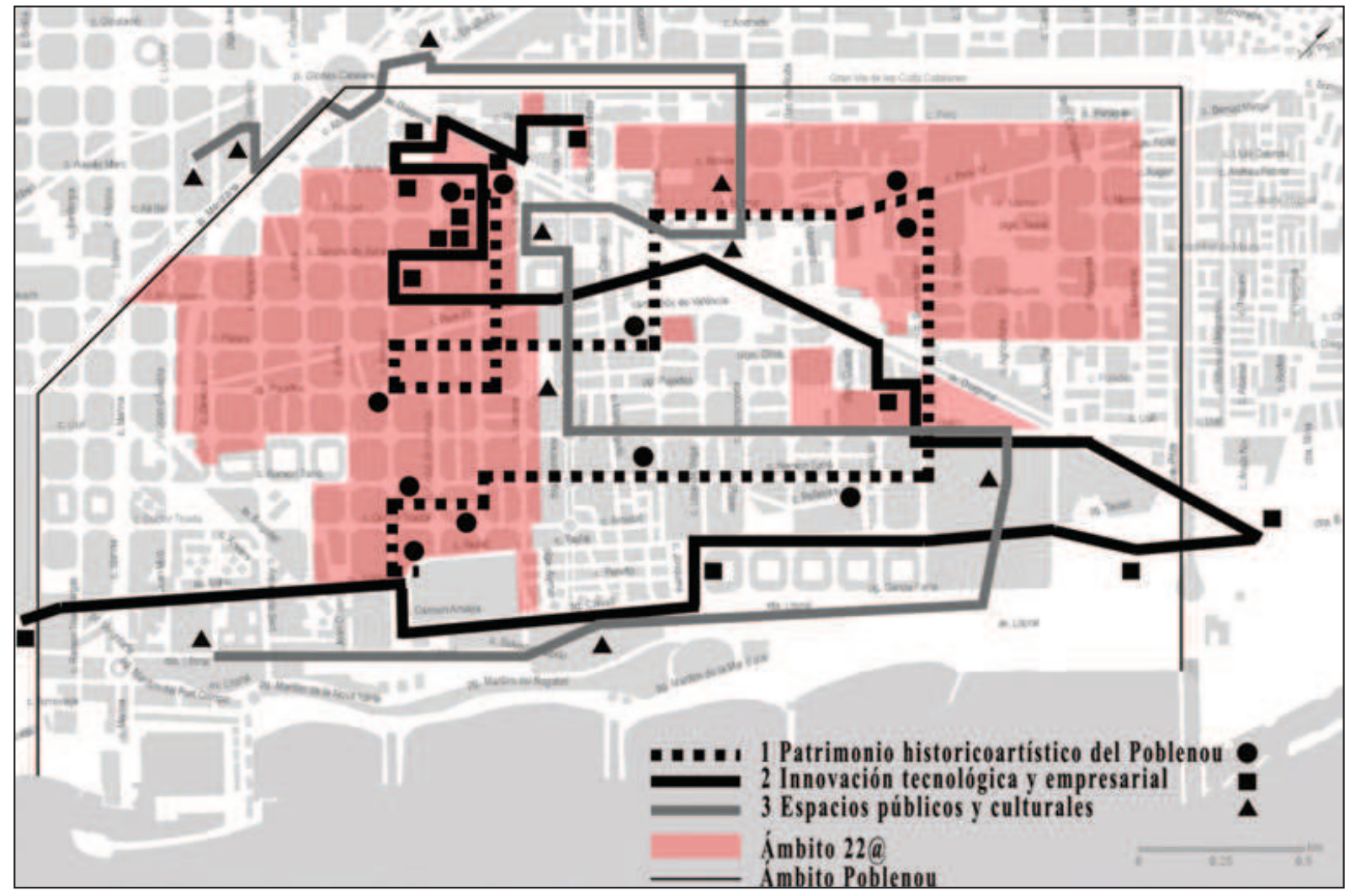

Fuente: Elaboración propia a partir de 22@Barcelona (2014).

En el itinerario 1 hay una selección de elementos arquitectónicos de la época de esplendor de la industria textil en el Poblenou, que pone en valor el patrimonio industrial. Se trata de edificios construidos a medianos y finales del siglo diecinueve donde se desarrollaba una actividad variada y complementaria de blanqueo y estampado de tejidos (Can Felipa, Can Saladrigas), de manufactura del algodón (Ca l'Aranyó), de producción de maquinaria textil y de géneros de punto (Can Tiana/Can Canela), de elaboración de productos químicos para la industria textil (La Escocesa), almacén de paños de Francesc Munné. En otros casos, se trataba de una antigua destilería (Passatge del Sucre) o de fábricas harineras (Can Gili Vell, Can Gili Nou) (Figuras 4, 5 y 6).

En el itinerario 2 se propone un recorrido para visualizar la ciudad tecnológica y empresarial con las actividades intensivas en conocimiento que forman parte del espacio productivo@. Entre los puntos de visita destaca por su patrimonio industrial el edificio de Can Jaumandreu, que desde mediados del siglo diecinueve tuvo una actividad ligada al blanqueo y estampado de tejidos. 
Figura 4

CAN GIL VELL, LOFT

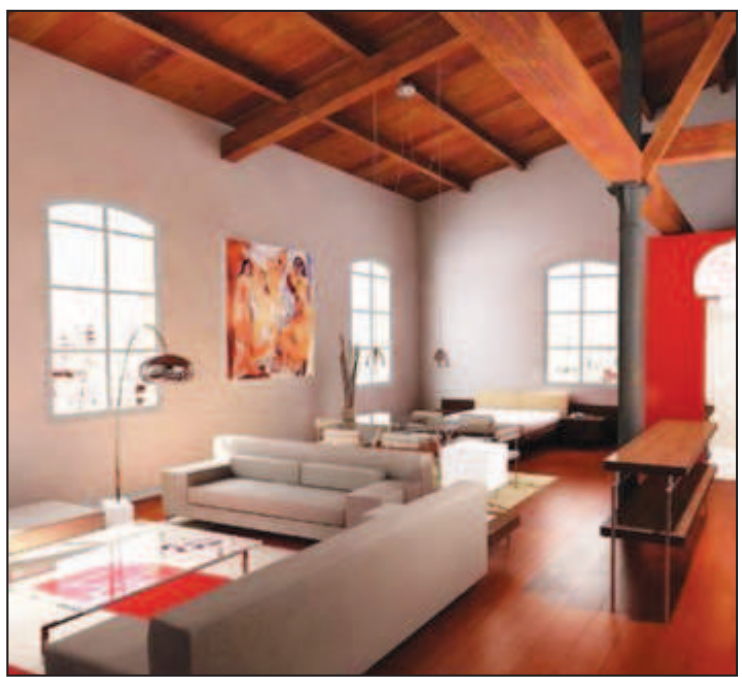

Fuente: Habitaclia.
Figura 5

CAN SALADRIGAS, BIBLIOTECA MANUEL ARRANZ

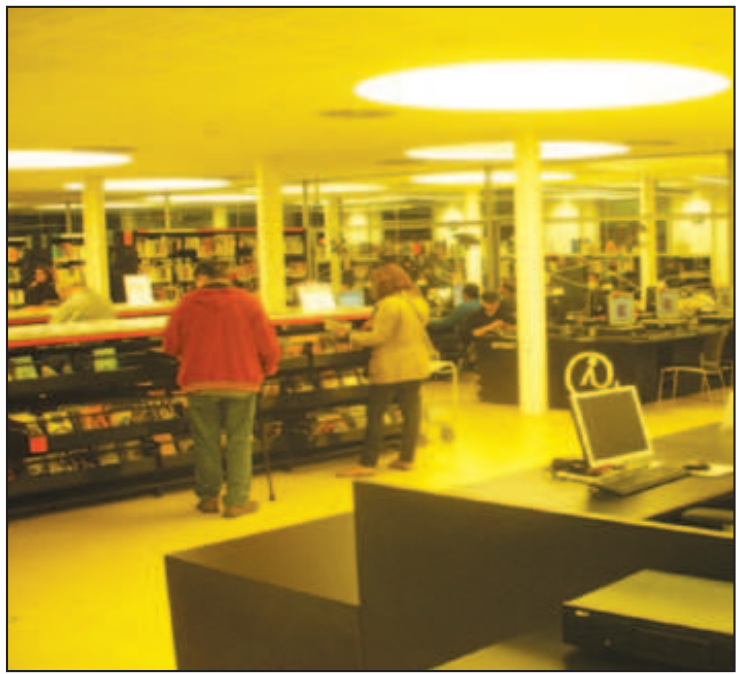

Fuente: elaboración propia (2014). Figura 6

FRANCESC MUNNÉ, ESCUELA SUPERIOR DE DISEÑO BAU

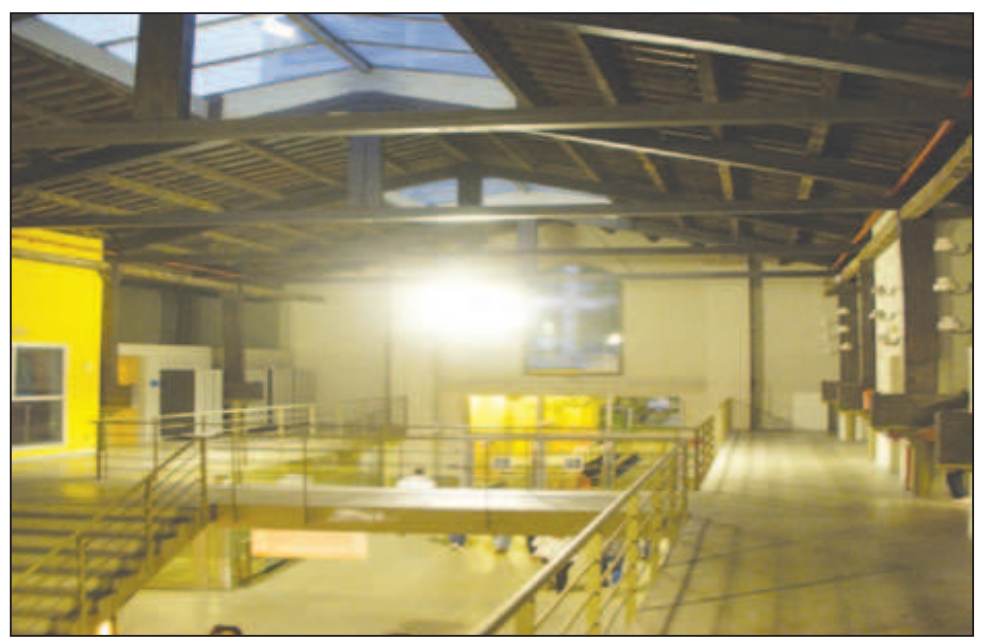

Fuente: elaboración propia (2014).

El itinerario 3 es una propuesta de equipamientos culturales y de espacios públicos que configuran la morfología del Poblenou. Tres de los puntos de interés del itinerario son edificios construidos a medianos y finales del siglo diecinueve dónde se desarrollaba la actividad de blanqueo y estampados de tejidos de Can Ricart (Dot et al., 2012); la industria harinera de La Farinera del Clot; y la antigua manufactura del algodón de Can Framis.

\section{ANÁLISIS DE LA TRANSFORMACIÓN DEL PATRIMONIO INDUSTRIAL ARQUITECTÓNICO A USO RESIDENCIAL: PASSATGE DEL SUCRE, CAN GILI VELL, CAN GILI NOU}

La normativa del plan22@Barcelona listó en el anexo «Edificios industriales reutilizables para la vivienda» los 18 edificios industriales proyectados para su nuevo uso residencial 
(2000), y especificó que el nuevo uso no debía desvirtuar las características arquitectónicas originales. Las actuaciones en edificios industriales existentes para el uso residencial no contemplan otras tipologías que las viviendas de la tipología loft. Según las normas urbanísticas:

«Amb l'objectiu d'incentivar la preservació del patrimoni arquitectònic industrial i de possibilitar una oferta d'habitatge tipològicament no convencional [loft], podran autoritzar-se actuacions de rehabilitació i/o reforma d'edificis industrials existents que prevegin la seva reutilització per a l'ús d'habitatge» (Ajuntament de Barcelona, 2000a:8).

Concretamente, el proceso de cambio de funcionalidad en cada promoción tiene que pasar por la aprobación de un Plan de Mejora Urbana (PMU), donde se establecen las actuaciones respecto a la rehabilitación y reforma del edificio industrial existente a vivienda loft. El PMU asigna una edificabilidad máxima de $2,2 \mathrm{~m}^{2}$ de techo/ $\mathrm{m}^{2}$ sobre parcela, que es menor comparada con los $3 \mathrm{~m}^{2}$ de techo/ $\mathrm{m}^{2}$ sobre parcela en la vivienda de protección oficial; y es el que establece una reserva de $31 \mathrm{~m}^{2}$ por cada $100 \mathrm{~m}^{2}$ de techo de vivienda para espacios libres y equipamientos, de los cuales $18 \mathrm{~m}^{2}$, como mínimo, se destinarán a espacios libres. La cesión de estos a la entidad municipal es obligatoria (Ajuntament de Barcelona, 2006).

Los edificios Passatge del Sucre, Can Gili Vell y Can Gili Nou son casos pioneros en Barcelona como edificios reutilizados como loft de acuerdo con la normativa del plan 22@ Barcelona que contempla específicamente este tipo de reutilización. Además constituían el principio de un nuevo paradigma en la rehabilitación de patrimonio en la ciudad. Hasta entonces la cultura constructiva y de promoción de viviendas en Barcelona proponía construcciones de nueva planta.

Entre los años 2003 y 2005 tres promotores de vivienda privados realizaron las adaptaciones y reformas basándose en los PMU (Tabla 1), aprobados por la Comisión Técnica del Ayuntamiento de Barcelona.

El Pla de Millora Urbana al Passatge Mas de Roda núm. 5-13 i 6-14. Passatge del Sucre (Ajuntament de Barcelona, 2003) reguló el espacio del antiguo conjunto industrial de la Compañía de Industrias Agrícolas S.A. para readaptarlo como complejo de 29 lofts $\left(4.455 \mathrm{~m}^{2}\right.$ de techo; clave urbanística 22@T1), además de oficinas (4.458 m² de techo;22@T2).

El Pla de Millora Urbana (PMU) de la Farinera La Fama (Ajuntament de Barcelona, 2004) permitió el desarrollo urbanístico del espacio conocido popularmente como Can Gili Vell con la rehabilitación y reforma como loft (5.269 m² de techo; clave urbanística 22@T1), además de oficinas (9.300 m² de techo; 22@T2).

El Pla de Millora Urbana de l'illa delimitada pels carrers Taulat 3. Ciutat de Granada 1-5 i Doctor Trueta 164 (Ajuntament de Barcelona, 2005), hizo posible el desarrollo urbanístico de la antigua Farinera de Josep Gili i Guardiola, conocida popularmente como Can Gili Nou. El PMU permitió la rehabilitación y reforma como loft $\left(6.009 \mathrm{~m}^{2}\right.$ de techo; clave urbanística 22@T1), y una construcción nueva destinada a uso hotelero (4.644 $\mathrm{m}^{2}$ de techo; 22@T2).

El elemento patrimonial industrial de los edificios de nueva vivienda loft constituyó un aspecto primordial para su promoción y venta. Frases como «respetando el concepto arquitectónico primitivo de las naves industriales», «prestando atención a los elementos 
originales tales como la volumetría, la fachada, las alturas, las ventanas de grandes dimensiones, y los elementos estructurales» (g56, 2012; Habitaclia, 2012; Luxury Properties, 2012) fueron frases claves en la promoción de las viviendas. Por lo que añadieron valor al producto final, reflejado en el precio de venta del loft, más elevado que el de vivienda más tradicional (Tabla 2), entre 4.421 y $6.640 € / \mathrm{m}^{2}$, comparado con $3.799 € / \mathrm{m}^{2}$, respectivamente (Fotocasa, 2012).

Tabla 1

NÚMERO DE LOFTS Y NIVEL DE PROTECCIÓN EN EL CATÁLOGO
DE LOS EDIFICIOS INDUSTRIALES

\begin{tabular}{|c|c|c|c|}
\hline PROMOCIÓN & $\begin{array}{c}\text { APROVACIÓN } \\
\text { PMU }\end{array}$ & $\begin{array}{c}\text { NIVEL DE } \\
\text { PROTECCIÓN EN } \\
\text { EL CATÁLOGO }\end{array}$ & $\begin{array}{l}\text { NÚMERO DE } \\
\text { VIVIENDAS } \\
\text { TIPO LOFT }\end{array}$ \\
\hline $\begin{array}{l}\text { Passatge del Sucre } \\
\text { (Passatge Mas de Roda, 5-13 y 6-14) }\end{array}$ & $\begin{array}{l}\text { Año: } 2003 \\
\text { Promotor: } \\
\text { Passatge } \\
\text { del Sucre SL }\end{array}$ & $\mathrm{C}$ & 29 \\
\hline $\begin{array}{l}\text { Can Gili Vell } \\
\text { (c/ Ciutat de Granada 12b-16 / Ptge } \\
\text { Mas de Roda 22-36 / c/ Doctor } \\
\text { Trueta 167-183 y c/ Roc Boronat } \\
\text { 11-17) }\end{array}$ & $\begin{array}{l}\text { Año: } 2004 \\
\text { Promotor: } \\
\text { Riofisa }\end{array}$ & $\mathrm{C}$ & 56 \\
\hline $\begin{array}{l}\text { Can Gili Nou } \\
\text { (c/ Taulat 3-13 y c/ Ciutat de Granada } \\
\text { 1-5) }\end{array}$ & $\begin{array}{c}\text { Año: } 2005 \\
\text { Promotor: Grupo } \\
\text { Kanda } \\
\text { (Altabadia, SL) }\end{array}$ & B & 54 \\
\hline
\end{tabular}

Fuente: Elaboración propia (2014) a partir de Ayuntamiento de Barcelona (2003, 2004, y 2005).

Tabla 2

SITUACIÓN DEL MERCADO INMOBILIARIO DE PROMOCIÓN PRIVADA-LOFT EN EL POBLENOU

\begin{tabular}{|c|c|c|c|c|}
\hline $\begin{array}{c}\text { VIVIENDA EN EL } \\
\text { EDIFICIO }\end{array}$ & $\mathrm{M}^{2}$ & $€ / \mathrm{M}^{2}$ & PRECIO $(€)$ & $\begin{array}{c}\text { COMPARATIVA CON PRECIO } \\
\text { MEDIO DEL POBLENOU } \\
\left(3.799 € / \mathrm{M}^{2}\right)\end{array}$ \\
\hline Passatge del Sucre & 138 & 4.529 & 625.000 & $(+) 19 \%$ \\
\hline Passatge del Sucre & 101 & 5.050 & 510.000 & $(+) 33 \%$ \\
\hline Passatge del Sucre & 169 & 4.421 & 725.000 & $(+) 16 \%$ \\
\hline Passatge del Sucre & 125 & 5.814 & 750.000 & $(+) 53 \%$ \\
\hline Farinera de Can Gili Vell & 54 & 6.640 & 358.588 & $(+) 74 \%$ \\
\hline Farinera de Can Gili Nou & 79 & 5.266 & 416.000 & $(+) 39 \%$ \\
\hline
\end{tabular}

Fuente: Elaboración propia a partir de Fotocasa (2012) y Departament de Estadística de Barcelona (2012). 


\section{ANÁLISIS DE LOS ELEMENTOS PATRIMONIALES COMO INCENTIVOS PARA LA PROMO- CIÓN TURÍSTICA}

Uno de los sectores que más se ven atraídos por una morfología urbana que simbolice como se yuxtaponen diferentes épocas en un mismo espacio es el turismo. Partimos de la hipótesis que el turista viene a Barcelona para visitar la ciudad, en su conjunto, y sus símbolos más representativos en particular. A partir del año 2000, que el Ayuntamiento empieza a desarrollar un nuevo concepto de «barrio» como distrito tecnológico, surgen y se forman nuevos símbolos que incorporan el espacio Poblenou-22@Barcelona a la oferta turística de la ciudad. Este proceso de construcción se añade a la Barcelona simbólica complementándola. Por ejemplo, la torre AGBAR, inaugurada en el 2005, el Parc Central (parte del antiguo Can Ricart), en el 2008, el Museo Fundació Vila Casas (antes Can Framis) y la Biblioteca Saladrigas (Can Saladrigas) en el 2009. Por tanto, la reforma del Poblenou hacia un espacio tecnológico, incluía, además la construcción de la Barcelona simbólica que incorporó, al mismo tiempo, el elemento patrimonial como valor añadido.

Lo interesante de este proceso es que originalmente una zona periférica como el Poblenou, con funciones obsoletas y con su pasado industrial se convierte en un atractivo más de Barcelona; y juntamente con procesos adyacentes, como la remodelación de la anilla de la Plaça de les Glòries (2014), la construcción del edificio Disseny Hub Barcelona (2012), de 1'Auditori (1999) y del Teatre Nacional (1997) contribuyen a la compacidad urbana. Se podría pensar en este proceso como un «Nuevo Modelo Barcelona» con sinergias obtenidas desde procesos diferentes, con luces y sombras, pero con un original planteamiento de como impulsar nuevas centralidades e incrustarlas territorialmente, socialmente y culturalmente a la ciudad.

El proyecto Poblenou-22@Barcelona incluyó la construcción de hoteles y la rehabilitación de edificios. Por lo que el visitante o turista ${ }^{8}$, podría alojarse en este espacio, puesto que hay oferta hotelera, y, al mismo tiempo visitar los elementos de patrimonio industrial y los nuevos símbolos creados. Para analizar cómo se habían incorporado los nuevos símbolos de patrimonio industrial a la oferta turística de Barcelona se analizaron la Guía para visitar y descubrir el distrito 22@Barcelona, en la que aparecen itinerarios muy detallados sobre patrimonio industrial; y 8 guías turísticas on line a partir del buscador Google. El criterio de búsqueda en éstas incluyó las palabras 'Guía de viaje turístico Barcelona' y 'Guía de viaje turístico Poblenou'. El resultado permitió ver que el Poblenou estaba referenciado en 7 de ellas como punto de atracción turística. En 4 de ellas, los elementos de visita destacados correspondían al turismo de playa. En 2 casos, la torre AGBAR era destacada como objeto de interés especial. En 1 aparecía anunciado el Poblenou por su oferta hotelera y de restauración, por el Parc del Centre del Poblenou. Y en ninguna de ellas aparecía como elemento de visita el patrimonio industrial (Tabla 3).

8 Según la Organización Mundial de Turismo el visitante turista corresponde a aquella actividad que realizan las personas durante sus viajes y estancias en lugares distintos al de su entorno habitual, por un período de tiempo consecutivo inferior a un año, con fines de ocio, por negocios y otros motivos; mientras que el visitante excursionista corresponde a aquella actividad que realizan las personas que no comporta pernoctación (Organización Mundial de Turismo, 2014). 
Tabla 3

RESULTADOS OBTENIDOS EN EL BUSCADOR GOOGLE

\begin{tabular}{|c|c|c|c|c|c|}
\hline \multicolumn{3}{|c|}{$\begin{array}{c}\text { A partir del criterio } \\
\text { 'guía de viaje turístico Barcelona' }\end{array}$} & \multicolumn{3}{|c|}{$\begin{array}{c}\text { A partir del criterio } \\
\text { 'guía de viaje turístico Poblenou' }\end{array}$} \\
\hline \multirow[t]{2}{*}{ WEB } & \multicolumn{2}{|c|}{$\begin{array}{c}\text { ¿Aparece el } \\
\text { Poblenou como } \\
\text { lugar de interés? }\end{array}$} & \multirow[t]{2}{*}{ WEB } & \multicolumn{2}{|c|}{$\begin{array}{l}\text { ¿Aparece el Poblenou } \\
\text { como lugar de interés? }\end{array}$} \\
\hline & NO & Sí & & NO & Sí \\
\hline www.viajarabarcelona.org & & $\mathrm{X}$ (playas) & www.viajarabarcelona.org & & $\mathrm{X}$ (playas) \\
\hline www.barcelona-tourist-guide.com & & $\begin{array}{c}\text { X (playas, } \\
\text { hoteles) }\end{array}$ & www.turismoafondo.com & & $\begin{array}{c}\text { X (Parque } \\
\text { del Poblenou, } \\
\text { Parque del } \\
\text { Centre del } \\
\text { Poblenou } \\
\text { Playas) }\end{array}$ \\
\hline www.conocerbarcelona.com & & $\begin{array}{c}\text { X (playas, } \\
\text { AGBAR) }\end{array}$ & www.es.barcelona.com & & $\mathrm{X}$ (restaurantes) \\
\hline www.101viajes.com & $\mathrm{X}$ & & www.oh-barcelona.com & & $\mathrm{X}(\mathrm{AGBAR})$ \\
\hline
\end{tabular}

Fuente: Elaboración propia a partir del buscador http://www.google.es (Consulta: 31 de octubre de 2014).

Para averiguar cómo consumían los visitantes la oferta del Poblenou, se confeccionó una encuesta a 15 directores de hoteles (año 2012). Entre otros elementos, se preguntaba por el perfil de los visitantes, qué información se les daba sobre puntos de interés para visitar; y, finalmente, que valoración hacían los clientes sobre la visita que habían realizado. Los visitantes españoles eran un $27 \%$ del total; los europeos, exceptuando españoles, constituían una mayoría (52\%). Los visitantes por motivos de trabajo constituían un $48 \%$; mientras que por motivo de turismo eran un $45 \%$. Un $66 \%$ del total eran hombres (Tabla 4).

Tabla 4

PERFIL DEL VISITANTE ALOJADO EN EL HOTEL DEL POBLENOU

\begin{tabular}{|l|c|}
\hline \multicolumn{2}{|c|}{ Según la procedencia o nacionalidad (\%): } \\
\hline Español & 27 \\
\hline Europeo (no español) & 52 \\
\hline Otros & 21 \\
\hline Total Según motivo del viaje (\%): \\
\hline \multicolumn{2}{|c|}{100} \\
\hline Vacacional & 45 \\
\hline Profesional & 48 \\
\hline Otros & 7 \\
\hline Total & 100 \\
\hline
\end{tabular}




\begin{tabular}{|l|c|}
\hline \multicolumn{2}{|c|}{ Según sexo (\%): } \\
\hline Hombres & 66 \\
\hline Mujeres & 34 \\
\hline Total & 100 \\
\hline \multicolumn{2}{|c|}{ Según edad (\%): } \\
\hline $0-25$ años & 9 \\
\hline 26-65 años & 71 \\
\hline$>65$ años & 20 \\
\hline Total & 100 \\
\hline
\end{tabular}

Fuente: Elaboración propia (2012).

A la cuestión de qué información se proveía al visitante, los directores manifestaron que se ofrecían datos más dirigidos a la oferta comercial y de playas que a los atractivos de patrimonio, culturales y de espacios públicos que podía ofrecer el Poblenou-22@Barcelona. Los informantes dan a conocer mayoritariamente los centros comerciales y las playas en un $73 \%$ de los casos. El entorno empresarial e innovador en un $60 \%$, y los espacios públicos (excluyendo parques y playas) en un 53\%. Mientras que en arquitectura y patrimonio, parques, y museos sólo se da información en un 33\%, un 27\%, y en un 7\%, respectivamente (Tabla 5).

Tabla 5

PUNTOS DE INTERÉS DEL POBLENOU QUE SON RECOMENDADOS POR PARTE DEL HOTEL AL VISITANTE

\begin{tabular}{|l|c|c|c|c|}
\cline { 2 - 5 } \multicolumn{1}{c|}{} & \multicolumn{3}{c|}{ en \% } \\
\hline Puntos de interés que se recomiendan: & Siempre & Ocasional & Nunca & Total \\
\hline $\begin{array}{l}\text { 1. Arquitectura y Patrimonio histórico (Ca l'Aranyó, Can } \\
\text { Felipa, Can Saladrigas, Palo Alto) }\end{array}$ & 33 & 0 & 67 & 100 \\
\hline $\begin{array}{l}\text { 2. Entorno empresarial innovador 22@ (Torre AGBAR, } \\
\text { Parc Barcelona Media, Edifici Media-TIC, CMT, CINC) }\end{array}$ & 60 & 33 & 7 & 100 \\
\hline $\begin{array}{l}\text { 3. Espacio público (Rambla del Poblenou, Paseo } \\
\text { Marítimo, Marià Aguiló) }\end{array}$ & 53 & 40 & 7 & 100 \\
\hline $\begin{array}{l}\text { 4. Parques públicos (Parc Central, Diagonal Mar, Parc del } \\
\text { Centre del Poblenou) }\end{array}$ & 27 & 47 & 27 & 100 \\
\hline 5. Museos (Fundació Vila Casas) & 7 & 27 & 67 & 100 \\
\hline 6. Playas & 73 & 27 & 0 & 100 \\
\hline 7. Zona comercial (centros comerciales) & 73 & 27 & 0 & 100 \\
\hline 8. Zona comercial (pequeño comercio, Mercat de la Unió) & 13 & 60 & 27 & 100 \\
\hline
\end{tabular}

Fuente: Elaboración propia (2012).

Finalmente, entre los aspectos más valorados del Poblenou por los visitantes se encontraba la oferta de transporte público (8,5 sobre 10), el carácter de los ciudadanos $(8,3$ sobre 10) y la oferta hotelera ( 8 sobre 10). Las características urbanísticas y arquitectónicas junto a la oferta cultural y de ocio estaban también entre los aspectos mejor puntuados ( 7 sobre 10). Entre los puntos con menos puntuación se encontraba la limpieza, además de la contaminación atmosférica, los ruidos, y la seguridad ciudadana (Tabla 6). 
Tabla 6

Opinión del visitante sobre diferentes aspectos del Poblenou (escala del 1 (mala) al 10 (excelente))

\begin{tabular}{|l|c|}
\hline Aspecto valorado: & Valoración \\
\hline 1. Oferta arquitectónica & 7 \\
\hline 2. Ocio y entretenimiento & 7 \\
\hline 3. Transporte público & 8,5 \\
\hline 4. Oferta restaurantes & 7 \\
\hline 5. Carácter de los ciudadanos & 8,3 \\
\hline 6. Infraestructuras & 6,5 \\
\hline 7. Señalización e información & 7,1 \\
\hline 8. Oferta hotelera & 8 \\
\hline 9. Seguridad ciudadana & 3,2 \\
\hline 10. Limpieza general & 5,2 \\
\hline 11. Contaminación atmosférica & 4,8 \\
\hline 12. Ruidos & 4,5 \\
\hline
\end{tabular}

Fuente: Elaboración propia (2012).

\section{CONCLUSIONES}

En las ciudades de origen industrial, las administraciones locales tienen entre sus retos fundamentales encontrar soluciones para la dinamización de áreas urbanas que se caracterizan por su pasado industrial. La propuesta de recuperar la vocación productiva de Poblenou como parte de la estrategia de Barcelona como ciudad simbólica, se plantea a partir de la creación de una plataforma de innovación económica, dónde el eje cultural se complementa con el científico, tecnológico, y residencial; funciones que en algunas ocasiones se ubican en edificios catalogados como patrimonio industrial. En este artículo, se ha planteado la pregunta estructural basada en analizar cómo se produce el patrimonio industrial, cómo se consume, y cuáles son los agentes que participan en ambos procesos; y cómo el patrimonio deviene un elemento básico del proceso de revitalización urbana en el proyecto $22 @$ Barcelona. El planeamiento y ejecución del proyecto ha estado a cargo de la sociedad público-privada, 22 ARROBA BCN, S.A.U. (2000), que gestionó y promocionó el patrimonio industrial a partir de regulaciones urbanísticas; que históricamente se remontaban a una primera ordenanza del año 1979. Posteriormente, intervienen tres figuras de planificación $(2000,2006)$, donde se perfilan el valor patrimonial y sus nuevas funciones.

Varios agentes han participado en la formación de la cultura patrimonial de conservación industrial en el Poblenou, las instituciones locales, las asociaciones cívico-sociales, y las inversiones privadas. El sector cívico-social fue muy activo reivindicando los espacios públicos en el proyecto durante los años 1990, que forzaron posteriormente modificaciones en las políticas públicas iniciales. Por ejemplo, la más importante fue la modificación del Pla especial del patrimoni arquitectònic històric $i$ artístic de la ciutat de Barcelona. Districte de Sant Martí. Patrimoni industrial del Poblenou. En el año 2000 había 36 edificios protegidos; en el año 2006, se añadieron 68 edificios que se destinaron a equipamientos socio-culturales (7a, 7b), actividades económicas y viviendas (22@), y equipamientos de apoyo a empresas (7@). El 
resultado más emblemático de las reivindicaciones de los agentes sociales fue conservar Can Ricart (Casellas, 2007; Martí, 2010; Dot et al, 2014); donde se evitó su destrucción total, se declaró como Bien de Interés Cultural Nacional (2008), se diseñó un parque público (2008), y parte restante de sus edificios están sujetos a calificaciones 22@,7@, aún no resueltas.

Los agentes privados han intervenido en inversiones hacia la promoción de vivienda, de hoteles y de empresas. A partir del año 2000 se calificaron 18 edificios patrimoniales como susceptibles de convertirse en viviendas loft. Las primeras promociones fueron Passatge del Sucre, Can Gili Vell y Can Gili Nou (2003-2005). Esto constituyó un cambio de paradigma constructivo en Barcelona, donde no había habido hasta el momento la reutilización de un espacio industrial protegido a vivienda. Además, el elemento patrimonial ha añadido valor para la venta de las viviendas.

El patrimonio industrial resultante de los procesos explicados forma parte de la iconicidad y simbolismo del nuevo paisaje turístico de Barcelona. Los visitantes turistas valoran positivamente la oferta arquitectónica y los atractivos históricos y estéticos que ofrece el Poblenou; pero aún no están correctamente visualizados en las guías turísticas o en la información que dan los hoteles como puntos de interés a visitar. Si estas deficiencias se subsanasen, la creciente proporción de visitantes turistas que está experimentando el Poblenou (Clarós, 2012; Castán, 2013; Negro, 2014), se podría ver motivado por los atractivos del patrimonio industrial; y la Guía para Visitar y Descubrir el Distrito 22@ Barcelona (2010) podría actuar como agente-puente, y ser una herramienta para el punto de información de los hoteles.

Los resultados en este artículo tienen la finalidad de analizar cómo se han construido elementos patrimoniales en las políticas públicas de promoción de Barcelona en su competencia global; y de como el patrimonio industrial intrínseco entra a formar parte de su capital simbólico. Es importante resaltar que el proceso de remodelación del área periférica del Poblenou juntamente con proyectos adyacentes, -la remodelación de la anilla de la Plaça de les Glòries (2014), la construcción del edificio Disseny Hub Barcelona (2012), de l'Auditori (1999) y del Teatre Nacional (1997)- contribuyen a la compacidad urbana de diferentes espacios anteriormente separados y degradados. A raíz de los resultados de este artículo, se deja para más adelante la investigación de este proceso como un «Nuevo Modelo Barcelona» con sinergias obtenidas desde procesos urbanísticos diferentes, con luces y sombras, pero con un original planteamiento de como impulsar nuevas centralidades e incrustarlas territorialmente, socialmente y culturalmente a la ciudad.

\section{BIBLIOGRAFÍA}

AJUNTAMENT DE BARCELONA (1979): Ordenança sobre protecció del patrimoni arquitectònic, històric i artístic de la ciutat de Barcelona. Barcelona, Ajuntament de Barcelona.

AJUNTAMENT DE BARCELONA (2000a): Modificació del Pla General Metropolità per a la renovació de les zones industrials del Poblenou-Districte d'Activitats 22@BCN. Barcelona, Ajuntament de Barcelona.

AJUNTAMENT DE BARCELONA (2000b): Pla especial del patrimoni arquitectònic històric $i$ artístic de la ciutat de Barcelona. Districte de Sant Martí. Patrimoni industrial del Poblenou. Barcelona, Ajuntament de Barcelona. 
AJUNTAMENT DE BARCELONA (2003): Pla de Millora Urbana al Passatge Mas de Roda núm. 5-13 i 6-14. Passatge del Sucre. Barcelona, Ajuntament de Barcelona.

AJUNTAMENT DE BARCELONA (2004): Pla de Millora Urbana de l'illa delimitada pels carrers Ciutat de Granada, Doctor Trueta, Roc Boronat i Passatge Mas de Roda. Farinera la Fama. Barcelona, Ajuntament de Barcelona.

AJUNTAMENT DE BARCELONA (2005): Pla de Millora Urbana de l'illa delimitada pels carrers Taulat 3. Ciutat de Granada 1-5 i Doctor Trueta 164. Barcelona, Ajuntament de Barcelona.

AJUNTAMENT DE BARCELONA (2006): Modificació del Pla especial del patrimoni arquitectònic històric $i$ artístic de la ciutat de Barcelona. Districte de Sant Martí. Patrimoni industrial del Poblenou. Barcelona, Ajuntament de Barcelona.

AJUNTAMENT DE BARCELONA (2010): 10 años de 22@: el distrito de la innovación. [En línea]. Barcelona, Ajuntament de Barcelona. <www.10x22barcelona.com/?lang=ca > [Consulta: 31 de octubre de 2014].

AJUNTAMENT DE BARCELONA (2014): Distrito 22@Barcelona. [En línea]. Barcelona, Ajuntament de Barcelona. <www.22barcelona.com> [Consulta: 31 de octubre de 2014].

ÁLVAREZ, M.A. (2010): «La protección del patrimonio industrial y la política territorial», en La protección del patrimonio histórico en la España democrática (Henares, I. L., coord.). Granada, Universidad de Granada, 31-54.

ARXIU HISTÒRIC DEL POBLENOU (2001): El Poblenou: més de 150 anys d»historia. Barcelona, Arxiu Històric del Poblenou.

ASHWORTH, G. J. y VOOGD, H. (1990): Selling the city: marketing approaches in public sector urban planning. Londres, Belhaven Press.

AYUNTAMIENTO DE MADRID (1997): Plan General de Ordenación Urbana de Madrid. Madrid, Área de Gobierno de Urbanismo y Vivienda del Ayuntamiento de Madrid.

BALIBREA, M. P. (2004): «Barcelona: del modelo a la marca». Forum de cultura, democratizem la democràcia. [En línea]. <http://www.e-barcelona.org>. [Consulta: 31 de octubre de 2014].

BENITO, P. (2002): «Patrimonio industrial y cultural del territorio». Boletín de la Asociación de Geógrafos Españoles, n 34, 213-228.

BENITO, P. (2010): «Industria y patrimonialización del paisaje urbano: la reutilización de las viejas fábricas», en Ciudad, territorio y paisaje: reflexiones para un debate multidisciplinar (Cornejo, C., Morán, J., y Prada, J., coords.). Madrid, Compañía Española de Reprograf, 354-366.

BIANCHINI, F. y PARKINSON, M. (1993): Cultural policy and urban regeneration: the west european experience. Manchester, Manchester University Press.

CABALLÉ, F. (2010): «Desaparece el barrio de Icaria, nace la Vila Olímpica» en Biblio $3 W$, vol. XV, núm. 895 (9). Universidad de Barcelona. Disponible en http://www.ub.es/ geocrit/b3w-895/b3w-895-9.htm.

CABALLÉ, F., GONZALEZ, R., y NAVAS, T. (1991): «Un catàleg d'arqueologia industrial: el cas del Poblenou». I Jornades d'Arqueologia Industrial de Catalunya. Barcelona, Museu d'Hospitalet de Llobregat, 39-43. 
CALDERÓN, B. (2007): «Nuevos usos para el patrimonio arquitectónico industrial en Valladolid: completar equipamientos y generar valor» en Scripta Nova, vol. XI, núm. 247. Universidad de Barcelona. Disponible en http://www.ub.es/geocrit/sn/sn-247.htm.

CANO, J. (2012): Historia del loft. [En línea]. Barcelona. <http://josepcanoblog.com/tag/ historia-del-loft/>. [Consulta: 31 de diciembre de 2012].

CAPEL, H. (1996): «La rehabilitación y uso del patrimonio histórico industrial». Documents d'Anàlisi Geogràfica, no 29, 19-50.

CASANELLES, E. (1988): Por unos museos de ciencia y tecnología. II Jornadas Sobre La Protección y Revalorización Del Patrimonio Industrial. Barcelona, Generalitat de Catalunya, 417-421

CASELLAS, A. (2007). «Gobernabilidad, participación ciudadana y desarrollo económico: adaptaciones locales a estrategias globales» en Scripta Nova. XI, núm. 243. Universidad de Barcelona. Disponible en http://www.ub.es/geocrit/sn/sn-243.htm.

CASELLAS, A. y PALLARES-BARBERA, M. (2009): «Public sector intervention in embodying new economy in inner urban areas: the Barcelona experience». Urban Studies, vol. $46, n^{\circ} 5-6,1137-1155$.

CASTÁN, P. (2013): «La Rambla del Poblenou emergeix com a polèmic passeig turístic». El Periódico [En línea]. 14 de abril de 2013. < http://www.elperiodico.cat/ca/noticias/barcelona/rambla-del-poblenou-emergeix-com-polemic-passeig-turistic-2364891>. [Consulta: 31 de octubre de 2014].

CHECA, M. (2007): «Geografías para el patrimonio industrial en España: el caso de Barcelona» en Scripta Nova, vol. XI, núm. 245 (32). Universidad de Barcelona. Disponible en http://www.ub.es/geocrit/sn/sn-24532.htm.

CLARÓS, S. (2007): «De la Ciutat dels Prodigis a la Barcelona social» en Biblio 3W, vol. XII, núm. 751. Universidad de Barcelona. Disponible en http://www.ub.es/geocrit/b3w751.htm.

CLARÓS, S. (2010): «La cara oculta del 22@», Carrer 115, nº 5.

CLARÓS, S. (2012): «El boom del turismo al barri», El Poblenou, nº 72, 2.

DEPARTAMENT D'ESTADÍSTICA (2014): Departamento de Estadística de Barcelona. [En línea]. Ayuntamiento de Barcelona. <www.bcn.es/estadistica/castella/index.htm>. [Consulta: 31 de octubre de 2014].

DOT, E., CASELLAS, A., y PALLARES-BARBERA, M. (2012): «Gentrificació productiva, desindustrialització i relocalització industrial». Treballs de la $S C d G, \mathrm{n}^{\circ}$ 73, 27-52.

DOT, E., CASELlAS, A., y PALLARES-BARBERA, M. (2014). «La ciudad emprendedora. Nuevas bases para el espacio urbano en crisis. El 22@Barcelona», en Geografía de la crisis económica en España (Albertos, J.M.; Alonso, J.L., Coord.). València: PUV, 691-716.

FLORIDA, R. (2002): The rise of the creative class. Nueva York, Basic Books.

FLORIDA, R. (2005): Cities and the creative class. Nueva York, Routledge.

FOTOCASA (2012): Portal inmobiliario Fotocasa. [En línea]. <www.fotocasa.es>. [Consulta: 31 de agosto de 2012].

GENERALITAT DE CATALUNYA (1993): Llei 9/1993, de 30 de setembre, del Patrimoni Cultural Català. Generalitat de Catalunya. DOGC n ${ }^{\circ}$ 1.807, 11 de noviembre de 1993. 
GÓMEZ, J. (2013): «Del patrimonio-paisaje a los paisajes-patrimonio». Documents d'Anàlisi Geogràfica, vol. 1, no 59, 5-20.

G56 (2012): Empresa de servicios G56. [En línea]. <www.g56.com>. [Consulta: 31 de agosto de 2012].

GRUP DE PATRIMONI INDUSTRIAL DEL FÒRUM RIBERA BESÒS (2005a): «Un patrimoni únic, un futur brillant, un model de fer ciutat. Can Ricart-Parc Central de Barcelona. Nou projecte", en Biblio $3 W$, vol. X, no 580. Universidad de Barcelona. Disponible en http://www.ub.es/geocrit/b3w-580.pdf.

GRUP DE PATRIMONI INDUSTRIAL DEL FÒRUM RIBERA BESÒS (2005b): "Proposta de Pla Integral de Patrimoni Industrial de Barcelona", en Biblio $3 W$, vol. X, n ${ }^{\circ} 581$. Universidad de Barcelona. Disponible en http://www.ub.es/geocrit/b3w-581.htm.

GRUP DE PATRIMONI INDUSTRIAL DEL FÒRUM RIBERA BESÒS (2006a): "Can Ricart. Proposta d'intervenció", en Biblio 3W, vol. XI, no 630. Universidad de Barcelona. Disponible en http://www.ub.es/geocrit/b3w-630.pdf.

GRUP DE PATRIMONI INDUSTRIAL DEL FORUM RIBERA BESÒS (Eds.) (2006b): Can Ricart. Patrimoni,innovació i ciutadania. Barcelona.

HABITACLIA (2012): Portal inmobiliario Habitaclia. [En línea]. <www.habitaclia.com>. [Consulta: 31 de agosto de 2012].

HAYWARD, D. (2006): Creative clusters: a critical examination of the processes behind and implications of the emergence of a creative cluster in Shoreditch, London. Trabajo fin de Máster dirigido por Simon Leonard. Portsmouth, Universidad de Portsmouth.

HOSTENCH, O. (2010): Les Formes de Control del Patrimoni Urbà a Barcelona. El cas de la Rambla de Poblenou. Trabajo fin de Máster dirigido por Fernando Álvarez. Barcelona, Universitat Politècnica de Catalunya.

HUDSON, K. (1963): Industrial Archaeology. An Introduction. Londres, Humanities Press.

ICOMOS (2014): The International Council for Monuments and Sites. [En línea]. <http:// www.icomos.org/>. [Consulta: 31 de octubre de 2014].

KRUEGER, R. y GIBBS, D. (2007): The sustainable development paradox. Urban political economy in the United States and Europe. Nueva York, The Guilford Press.

LlOYD, R. (2006): Neo-Bohemia. Art and Commerce in the Postindustrial City. New York, Routledge.

LUXURY PROPERTIES (2012): Portal inmobiliario Luxury Properties. [En línia]. <www. luxuryproperties.es>. [Consulta: 31 de agosto de 2012].

MARCHENA, M. J. (1998): Turismo Urbano y Patrimonio Cultural. Una perspectiva europea. Sevilla, Patronato Provincial de Turismo / Diputación de Sevilla.

MARTÍ, M. (2010). Economia del coneixement i noves polítiques urbanes. Conflictes, participació i aprenentatges en el cas 22@bcn. Tesis del Doctorado de Sociologia. Bellaterra, Universitat Autònoma de Barcelona.

MARX, K. (1986): «Outlines of the Critique of Political Economy», en Collected Works of Karl Marx and Frederick Engels: Volume 28. New York: International Publishers, 80.

MEATPACKING IMPROVEMENT ASSOCIATION (2014): Asociación de promoción de Meatpacking. [En línia]. <www.meatpacking-district.com>. [Consulta: 31 de octubre de 2014]. 
MUSTERD, S. y MURIE, A. (eds.) (2010): Making Competitive Cities. Oxford, WileyBlackwell.

NEGRO, M. (2014): Excuse me, where is the beach? Poblenou reducido a una tapa para turistas. [En línea]. Barcelona. < http://www.pintiparada.com/2014/08/11/excuse-mewhere-is-the-beach/> [Consulta: 31 de octubre de 2014].

OMT (2014): Organización Mundial de Turismo. [En línea]. <http://www2.unwto.org/es> [Consulta: 31 de octubre de 2014].

ORTÚÑEZ, P. P. (2009): «Patrimonio histórico industrial e historia económica». Areas, vol. 29, 39-49.

PALLARES-BARBERA, M. (2010): «Com canviar quan els canvis són difícils? Avantatges i desavantatges de la Barcelona competitiva des de l'economia simbòlica». Treballs de la Societat Catalana de Geografia, ${ }^{\circ}$ 69, 229-245.

PALLARES-BARBERA, M. y LEONARD, S. (2007): Clúster creatius en entorns urbans: 22@Bcn i Shoreditch East London. Generalitat de Catalunya, Agència de Gestió d'Ajuts Universitaris i de Recerca. <http://hdl.handle.net/2072/39306>. [Consulta: 31 de octubre de 2014].

PARDO, C. J. (2010): «El patrimonio industrial en España: análisis turístico y significado territorial de algunos proyectos de recuperación». Boletín de la Asociación de Geógrafos Españoles, $\mathrm{n}^{\circ}$ 53, 239-264.

PAREJA, M., TURMO, J., PRADEL, M., GARCIA, L., y SIMÓ, M. (2007): The city of marvels? Multiple endeavours towards competitiveness in Barcelona. Pathways to creative and knowledge-based regions. ACRE report WP2.2. Amsterdam, AMIDSt.

POLANYI, K. (2001): The Great Transformation: The Political and Economic Origins of our Time. Boston, Beacon Press.

RAMOS, M. (2007): El turismo cultural, los museos y su planificación. Gijón, Trea.

RICHARDS, G. (2001a): «The Development of Cultural Tourism in Europe» en Cultural Attractions and European Tourism (Richards, G., ed.). Nueva York, CABI International, 3-28.

RICHARDS, G. (2001b): «Creating a New Tourism?» en Turisme i Cultura. Debats del Congrés de Turisme Cultural (Saló Internacional del Turisme a Catalunya). Barcelona, Fundació Interarts, 61-66.

TATJER, M. (2005a): «Fontseré a Can Ricart. La fàbrica de Can Ricart i l'actuació de Josep Fontseré i Mestre» en Biblio 3W, vol. X, nº 607. Universidad de Barcelona. Disponible en http://www.ub.es/geocrit/b3w-607.htm.

TATJER M. (2005b): «Josep Oriol Bernadet (1811-1860) i la seva aportació a la ciencia, la tècnica i l'arquitectura del segle XIX» en Biblio $3 W$, vol. X, $\mathrm{n}^{\circ} 582$. Universidad de Barcelona. Disponible en http://www.ub.es/geocrit/b3w-582.htm.

TATJER, M. (2008): «El patrimonio industrial de Barcelona entre la destrucción y la conservación, 1999-2008» en Scripta Nova, vol. XII, nº 270 (140). Universidad de Barcelona. Disponible en http:/www.ub.edu/geocrit/sn/sn-270/sn-270-140.htm.

TATJER, M., URBIOLA, M., i GRUP DE PATRIMONI INDUSTRIAL DEL FORUM RIBERA BESÒS (2005): «Can Ricart. Estudi Patrimonial (Sintesi)» en Biblio 3W, vol. $\mathrm{X}, \mathrm{n}^{\circ}$ 598. Universidad de Barcelona. Disponible en http://www.ub.es/geocrit/b3w-598. htm. 
TICCIH (2003): Carta de Nizhny Tagil sobre el patrimonio industrial. [En línea]. 2003. $<$ www.international.icomos.org >. [Consulta: 31 de octubre de 2014].

TICCIH (2014): The International Committee for the Conservation of the Industrial Heritage [En línea]. 2012.<http://www.ticcih.org/>. [Consulta: 31 de octubre de 2014]

YEOH, B. (2005): «The global cultural city? Spatial imagineering and politics in the (multi) cultural marketplaces of South-east Asia». Urban Studies vol. 42, n ${ }^{\circ}$ 5-6, 945-958.

ZUKIN, S. (1989): Loft Living. Culture and Capital in Urban Change. Nueva York, Rutgers University Press. 